Hva tilfører denne artikkelen? Artikkelforfatterne har underlegevakten fremfor fastlegeni studie ved Legevakten i Arendal. som dekker ti kommuner med til sammen 86000 innbyggere.

\section{Hva vet vi fra før?}

Sykepleiere utgiør i dag den stør(Norsonellgruppen på legevakt svart forskjellig fra kommune

til kommune. llegevaktsentrale

g i mottaket på legevakt er det primært sykepleiere som møter pasientene og foretar de første vurderingene.

Nøkkelord

Nøkkelord
- Fastlege
- Legevakt
Mer om forfatterne: Eva Moe er utdannet sykepleier og har vært ansatt ved Legevakten Arendal siden 1995, de siste åre som enhetsleder. Gunnar Tschud drmed ved Institutt for allmenn- medisinske fag. Universitetet Bergen, og arbeider som forsker ved Nasjonalt kompetansesenter tmedisin. Kontakt
Bakgrunn: Legevakten i Arendal har vel 24000 konsultasjoner året. Vi ønsket å beskrive årsaker pasientene oppga for å velge legevakten fremfor fastlegen. Metode: Et spørreskjema ble delt ut til 761 av de 1776 pasientene som oppsøkte Legevakten Arendal i perioden 1.-31. mars 2007. Av disse var det 736192 prosent) som besvarte skjemaet. Data presenteres deskriptivt med prosentandeler.

Resultater: De tre vanligste arsakene pasientene oppga á oppsøke legevakten fremfor fastlegen var at fastlegekontoret var stengt, pasienten ble syk utenom vanlig kontortid, og legevakten. Over halvparten

Why do patients choose to attend the casualty clinic rather than their regular general practitioner?

Background: There are more than 24,000 consultations a year in the casualty clinic in Arendal, Norway. We wanted to study the patients reasons why they choose to attend the casualty clinic rather than their regular general practitioner (RGP)

Methods: Out of 1776 patients who attended the casualty clinic in Arendal in March 2007 which was filled in by 736 patients $(92 \%)$

Results: The three most common reasons the patients pasientene vurderte sin sykdom eller skade som alvorlig elle meget alvorlig. Vel 40 prosent mente det vanligvis ikke spilte noen rolle om det var fastlegen eller legevakten som ytte den hjelpen som trengtes. Nesten her tredje konsultasjon gjald barn og unge under 15 år. Bruken av legevakten avtok med kenende avs faste avstand ra pasientens fost lekektor noen legekontor oppsøkte legevakten i større grad enn pasien er fra liknende legekontor, me filnærmet lik listelengde og lik avstand til legevakten.

Konklusjon: Pasientenes bosted g fastlegekontor har stor betydning for legevakts $ø$ kning. Mange pasienter som oppsøker legevakten ønsker ikke å vente til time hos fastlegen neste dag. svært mange pasienter vurdere sine plager som alvorlige. reported for attending the casualty clinic were that the RGPs office was closed, the patient became ill after regular office hours, and patients could receive help sooner at the casualty clinic. More than half of the patients considered their illness or injury as rerious or very serious. More than $40 \%$ stated that than $40 \%$ stated that it does casualty clinic or the RGP that gives the medical help needed. Nearly every third consultatio was given to children below 15 years. Attendance at the casualty clinic decreased with increasing distance from the ocation of the RGPs office. We did however observe a substantial variation in attendance from patients belonging to RGP offices with comparable num ber of listpatients and similar distance to the casualty clinic. Conclusion: The location of the patient's residence and RGPs office was of great importance for the consultation rate at the casualty clinic. Many patients did not want to wait for the RGP office to open the following day. A large number of patients considered their medical problem as serious.

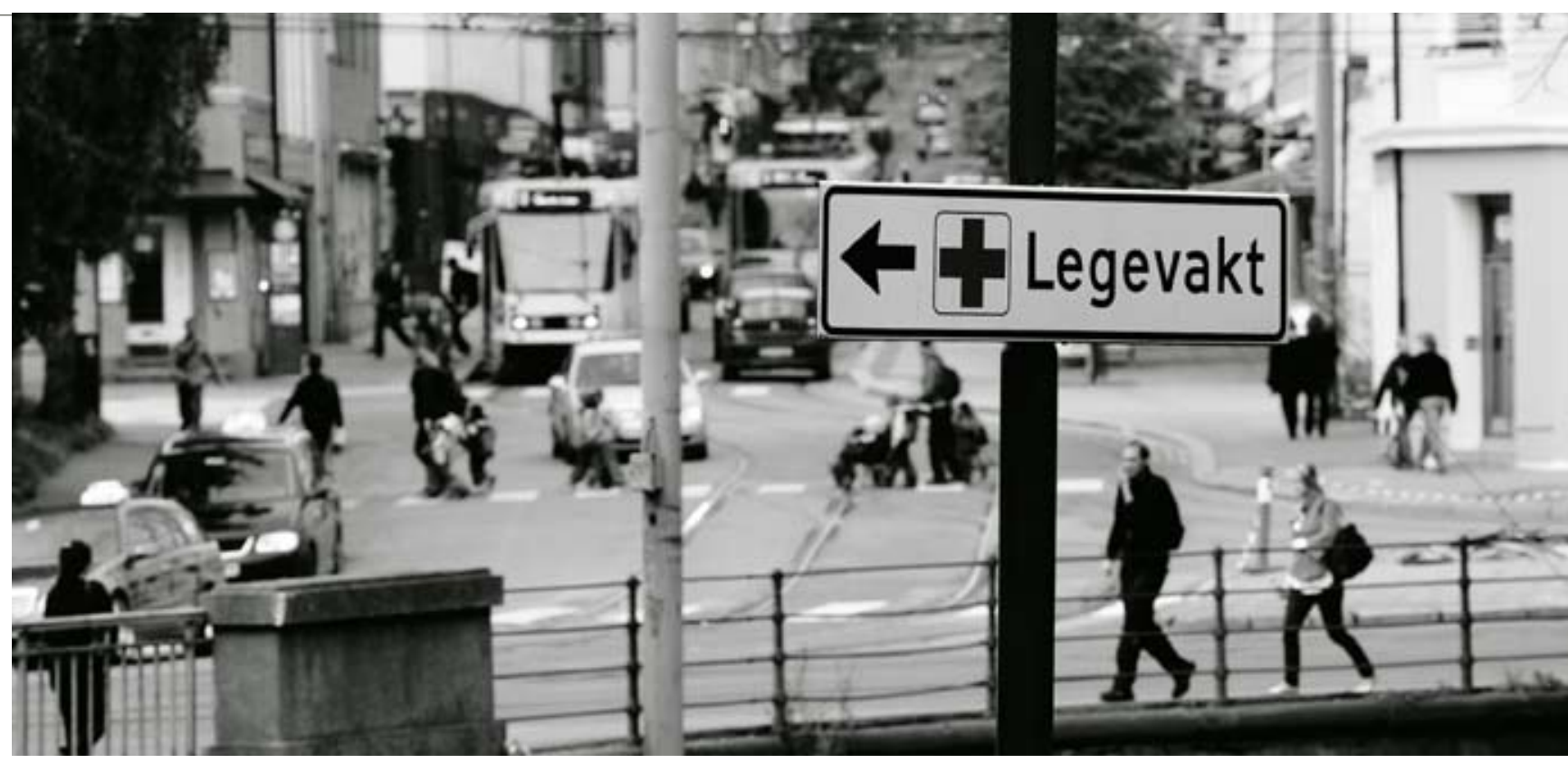

\title{
»Hvorfor velger pasienten legevakten fremfor fastlegen?
}

Tekst: Eva Moe g Gunnar Tschudi Bondevik

Foto: Erik Sundt

INTRODUKSJON

Ifølge Helse- og omsorgsdepartementet skal kommunene sørge for at nødvendige legeressurser er tilgjengelige på dagtid og at det er organisert legevakt hele døgnet. Ved akutt sykdom eller skade som oppstår kveld eller natt, kan legevakten kontaktes. Legevakten skal i hvert enkelt tilfelle vurdere om tiltak er nødvendig umid- delbart eller om behandling kan forsvarlig legevakttilbud av god

vente til neste dag slik at vedkom- kvalitet. Denne utviklingen ha mende

Mange kommunale legevakter sliter med å tilby sine innbyggere et faglig godt tilbud kveld og natt (2). Sosial- og helsedepartementet har siden 1999 oppfordret kommunene - og git onomisk støtte - til etablering inger (3). Hovedirsaken var a i kre res. Hovering slik at innbyggerne skulle få vært svært forskjellig i de ulike kommunene.

Legevakten i Arendal etablerte tidlig en interkommunal legevaktordning. Allerede 1. mars 2000 var det et legevaktsamarbeid mellom sju kommuner i Aust-Agder. Legevakten i Arendal er i das en interkommunal legevakt for ti kommuner, åtte kommuner Aust-Agder og to i Telemark. Aust-Agder og to i Telenark. legevaktdistriktet bor det 86000 langs kysten og knappe 14000 
i seks innlandskommuner. Legevakten er lokalisert på Sørlandet Sykehus i Arendal. To fjerntliggende, små kommuner har opptil to og en halv times kjøring til legevakten (15 mil lengste avstand). Legevakten hadde $2007 \mathrm{i}$ underkant av 24000 konsultasjoner. De fleste pasientene ringer og får tildelt et klokkeslett for oppmøte på legevakten. Pasienter som ikke er hjemmehørende i legevaktdistriktet, møter oftest direkte på legevakten uten å ha ringt på forhånd.

Ventetiden avhenger av alvorlighetsgraden. Alvorlighetsgrad deles inn i rød, gul og grønn respons etter Norsk index for medisinsk nødhjelp. Rød hastegrad (akutt) defineres som livstruende eller potensielt livstruende. Gul hastegrad (haster) defineres som en mulig alvorlig tilstand der vitale organer kan bli truet og det er behov for rask situasjonsvurdering av lege. Gronn hastegrad (vanlig) defines som tilstander kan vente til forste passende anledning (4)

Det kan være mange grunner til at pasientene velger legevakten fremfor fastlegen, og det var ønskelig å finne noen av disse årsakene. En undersøkelse fra Telemark viste at tre av ti barn under seks år hadde fät hielp fra legevakten i lopet av ett ar gen tredel av disse hede ikke forsøkt appsøke fastlegen først. En av arsakene kunne være at foreldrene hadde etablert en vane med a benytte legevakten som sitt faste legekontor.

Pasientenes bruk av legevakt er bare delvis en følge av tilgjengeligheten hos fastlegen. I en leder i Tidsskrift for Den norske legeforening fastslår Hasvold at

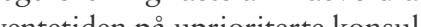
chict ned og at tilgangen på akuttimer hos fastlegen ikke er blitt bedre var å finne ut hvorfor pasienten etter at fastlegeordningen ble velger legevakten fremfor fastleinnført (6).

Man kan også tenke seg at torer som kan tenkes å påvirke innføringen av fastlegeordnin- pasientenes valg av legevakt fremen ville ført til en reduksjon i for fastlege i distriktet tilhørende pon

iste en underat. vaste en unden i Trokso fra 2001 at ger

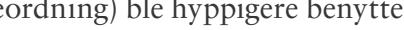
enn legevakten i Fredrikstad, som a var uten fastlegeordning (7). annen side fant Jøsendal elser ble redusert med 30 prosent ter inforing av fastegerosent av fastlegerdninRadøy kommune (8).

Hensikten med denne studie

\section{METODE}

I perioden 1.-31. mars 2007 delte sykepleierne ut et spørreskjema til pasienter som kom til legekonsultasjon ved Legevakten i Arendal. Spørreskjemaet ble utformet pà grunnlag av andre brukerundersøkelser, og hadde egen forside soker, og hadde egen forside pasienten. Det var totalt 14 sporsmål med ulike svaralternativ og

TABELL 1: Årsaker til at pasienten valgte å oppsøke legevakten remfor fastlegen akkurat den dagen. N=717 (mulighet for å krysse av på flere alternativl

\begin{tabular}{l|c|c}
\hline Årsaker & Ja & $\%$ \\
\hline Stengt fastlegekontor & 508 & 71 \\
\hline $\begin{array}{l}\text { Ble syk utenom vanlig } \\
\text { kontortid }\end{array}$ & 272 & 38 \\
\hline $\begin{array}{l}\text { Raskere å få hjelp på } \\
\text { legevakten }\end{array}$ & 85 & 12 \\
\hline $\begin{array}{l}\text { Praktisk vanskelig } \\
\text { å gå til fastlegen på } \\
\text { dagtid }\end{array}$ & 56 & 8 \\
\hline $\begin{array}{l}\text { Fikk ikke time fort nok } \\
\text { hos fastlegen }\end{array}$ & 44 & 5 \\
\hline $\begin{array}{l}\text { Tror ikke fastlegen } \\
\text { yter den hjelpen som } \\
\text { trengs akkurat nå }\end{array}$ & 37 & 3 \\
\hline $\begin{array}{l}\text { Har fastlege i annet } \\
\text { distrikt }\end{array}$ & 21 & 2 \\
\hline $\begin{array}{l}\text { Kom ikke gjennom på } \\
\text { telefon til fastlegen }\end{array}$ & 18 & 2 \\
\hline $\begin{array}{l}\text { Fastlegekontoret ba } \\
\text { meg oppsøke lege- } \\
\text { vakten }\end{array}$ & 16 & 1 \\
\hline $\begin{array}{l}\text { Vil selv bestemme når } \\
\text { jeg skal gå til lege }\end{array}$ & 12 & 1 \\
\hline $\begin{array}{l}\text { Dårlig erfaring fra } \\
\text { tadligere med å få tak i } \\
\text { fastlegen }\end{array}$ & 8 & 6 \\
\hline Har ikke fastlege & 6 & \\
\hline
\end{tabular}

mulighet for fritekstbesvarelse. $V_{i}$ ønsket informasjon om pasientens alder (år), kjønn og bostedskommune, samt ukedag, klokkeslett, navn på fastlegekontoret og hvilke grunner pasienten hadde for å oppsøke legevakten den aktuelle dagen (se tabell 1). Videre registrerte vi hvordan pasienten selv vurderte alvorlighetsgraden av den aktuelle sykdommen eller skaden (meget alvorlig, alvorlig, mindre alvorlig og vet ikke), om pasienten ville ha oppsakt legevakten dersom ha han var sikret time hos fa innen kort tid (ja, nei og vet ikke), og hvilken lege pasienten mente vanligvis var best til à gi nødvendig hjelp (fastlege, legevaktslege, fastlege eller legevaktslege - spiller ingen rolle, spesialist, andre og vet ikke). Spørsmålene skulle besvares mens pasienten ventet på å komme inn til legen. Små legekontor er her definert som egekontor med under 2000 listepasienter og store legekontor er definert som legekontor med over 4000 listepasienter.

Pasienter som ikke behersket norsk, som kom i følge med politi, som trengte hjelp umiddelbart eller som ikke kunne gjøre rede for seg ble ekskludert fra undersøkelsen. Før undersøkelsen ble det sendt ut et informasjonsbrev til alle legevaktleger og fastleger i distriktet. Alle sykepleier idistriktet. Alle sykepleierne ved legevakten ble informert om studien pà et personalmøte samt eget skriv. Etisk komité ble kontaktet, men siden prosjektet var en kartleggingsstudie av forekomst, var konklusjonen at studien ikke trengte behandling i komiteen.

Legevakten i Arendal er en av sju legevakter som deltar i Vakttårnundersøkelsen i regi av Nasionalt kompetansesenter for Nejont komp legevarturesin (9). Her rion ukedag, bostedskommune og hastegrad. Våre tall er sammen- ter som kom i følge med politiet ignet med tilsvarende tall fra Vakttar

Data ble analysert i statistik programmet SPSS, versjon 14.0 og presenteres deskriptivt med

\section{RESULTATER}

I mars 2007 ble det registrert 1776 legekonsultasjoner ved Legevakten i Arendal. Skjemaet ble delt ut til 761 pasienter $(43$ prosent). Av disse var det 736 92 prosent) som svarte. Pasien-

FIGUR 1: Aldersfordeling ved henvendelse til Legevakten i Arenda mars 2007. $n=761$

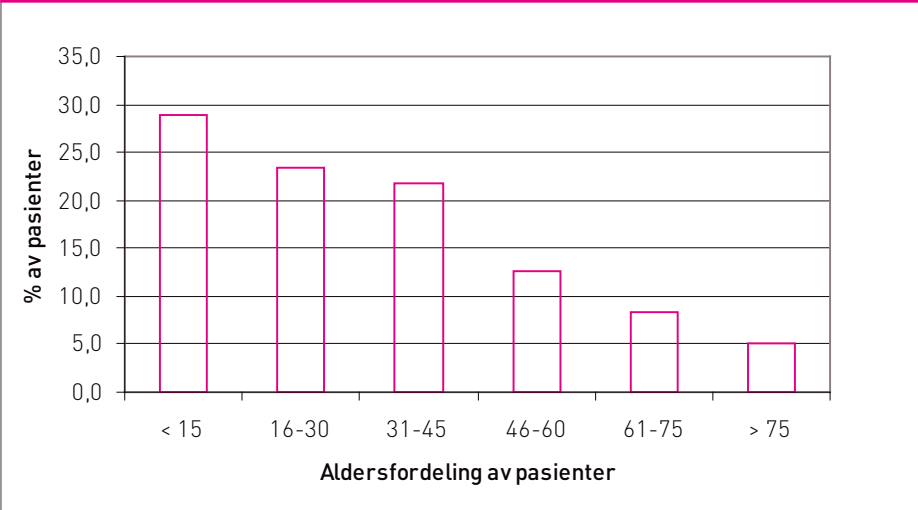

FIGUR 2: \% av listepasienter i ulike kommuner som oppsøkte LV Arendal i mars 2007. $n=616$

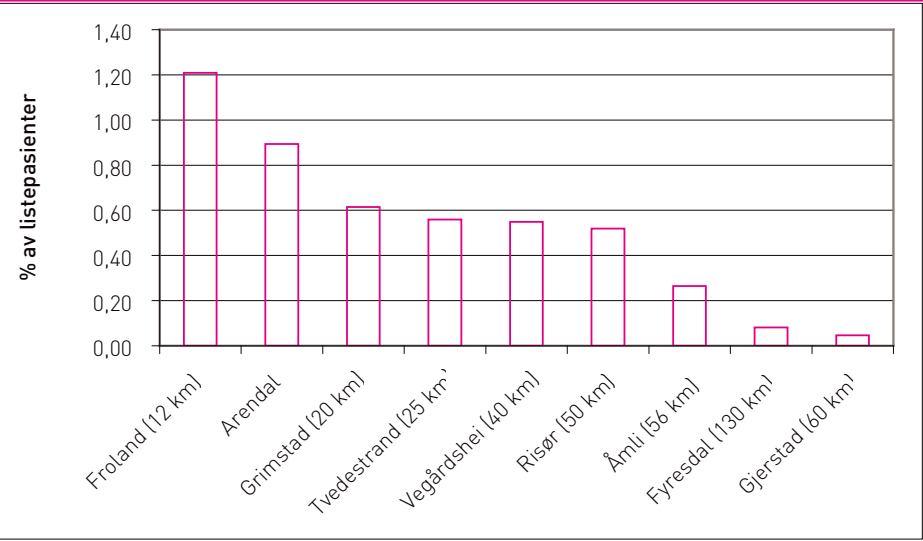


53 prosent gutter og i aldersgruppen 61-75 år var det 52 prosent menn. I de øvrige aldersgruppene var det flertall av kvinner.

Det var færrest pasienter som kom pa onsdager (6 prosent) og mandager ( 9 prosent) og flest på ørdager (27 prosent) og søndager (20 prosent). Tretti prosent møtte

\section{Over halvparten \\ av pasientene} vurderte sin tilstand da de kom til legevakten som alvorlig eller meget alvorlig.

mellom kl.08 og 15 og 62 prosent mellom kl.15 og 23 .

54 prosent av pasientene som oppsøkte legevakten, hadde bostedsadresse i Arendal, 18 prosentedsam fra Grimstad, 8 prosefra Froland, 6 prosent fra Risor 5 pront 6 Tvedest og 5 prosent fra Tvedestrand. Nesten alle pasientene, 724 av 760 (95 prosent), oppgav at hadde fastlege.

Den vanligste grunnen pasienten oppga til å oppsøke legevakten fremfor fastlegen den aktuelle dagen var at fastlegekontoret var stengt (71 prosent). Dernest svarte 38 prosent at de oppsokte legevakten fordi de var blitt syke gevakten fordi de var utenom vanilg kontortid, mens 12 prosent mente det var raskere à fa hjelp på legevakten og 8 prosen svarte at det var praktisk vanskelig å gå til fastlege på dagtid (tabell 1).

Av 705 pasienter vurderte 310 (44 prosent) sykdommen eller skaden de kom med på legevakten som alvorlig, mens 65 pasienter prosent) varderte den som mer prosent) varderte den son meget proser prosent) som vurderte tilstanden
som mindre alvorlig, mens 193 pasienter (27 prosent) oppga at listepasienter, mens 67 pasienter de ikke visste hvor alvorlig det kom fra et annet kontor i ArenPasienter tilh og og ner Arendal kommune oppsøkte legevakten oftest (antal Av de som vurderte sykdommen pasienter pà legevakten per 1000 eller skaden som mindre alvorlig, innbyggere i kommunen). Bruken svarte 40 prosent at de likevel av legevakten avtok med økende ikke var villige til å vente til neste avstand fra fastlegekontoret til dag, selv om de hadde vært sikret legevakten (avstand målt til komtime hos fastlegen da. Her var det munesentrene). De som brukte ingen forskjell mellom kvinner og legevakten sjeldnest (en gang per menn. I hele materialet ( $\mathrm{n}=706) \quad 1000$ innbyggere $\mathrm{i}$ kommunen), svarte 442 pasienter ( 58 prosent) var pasienter tilh svarte ville pasingeat de ville ha oppsøkt legevakten samme dag selv om de var sikre time hos fastlegen neste dag. Ku 157 pasienter (21 prosent) var villige til a vente til neste dag, mens 107 pasienter (14 prosent) ikk visste om de ville vente til neste dag.

Av 753 pasienter mente 288 (38 prosent) at fastlegen vanligvis best gir den hjelpen pasiente vasienten (1) hen hijpen pasienten trenger, (42 prosent) det ikke sill (42 prosent) mente eter er fastlegen eller legevakten som yter hjelpen. Knappe to tredele mente det er viktig å gå til en lege som kjenner pasienten.

Det var totalt 29 praksiser istriktet tilhørende Legevakten Arendal. Elleve praksiser va små legekontor med under 2000 to-legepraksiser (10). Det var sto ariasjon i andelen listepasienter re ulike legek listepasienter fra de ulike legekontor som oppsøkte legevakten. I forhold til istelengde kom det flest pasienter fra små legekontor i Arenda ommune. Også sammenliknbare legekontor, med tilnærmet likt antall listepasienter og lik avstand til legevakten, hadd lik søkning til legevakten. Fo eksempel kom det 39 pasienter fra et kontor i Arendal med vel 5000

\section{avstand til legevakten (figur 2).}

\section{DISKUSJON}

De to vanligste grunnene pasientene oppgav for å oppsøke legevakten i Arendal fremfor fastlegen, var at fastlegekontoret var stengt og at pasienten ble syk utenom vanlig kontortid. Disse svaralternativene er naturligvis ikke giensidig utelukkende. is ikke gjensidig utelukkende. Over halvparten av pasientene til legevakten som alvorlig eller meget alvorlig.

Nittifem prosent av pasientene svarte at de hadde fastlege. Dette er noe lavere enn andelen for hele landet (99 prosent) (11). Det er sannsynlig at pasienter uten fastlege i større grad benytmed fastlege. Videre et det fast var siden de aldri ha brukt eller hatt behov for a bre vedkommende og derfor har oppgitt at de ikke hadde fastlege.

Stengt fastlegekontor og at pasienten ble syk utenom vanlis kontortid er naturlige grunner til å oppsøke legevakten. For mange pasienter var begge forklaringene aktuelle. Nar 12 prosent svarte akture det var raskere a fa help på legevakten noe om manglende kapasitet hos ter seg av legevakt enn pasienter fastlegene for det som pasientene opplever som øyeblikkelig hjelp. I de tilfellene det ble oppgitt å være praktisk vanskelig å gå til fastlegen på dagtid, kan det neppe være stor grad av øyeblikkelig hjelp. I Werners undersøkelse i Arendal 2001 oppga hele fire femdeler av pasientene at akutt oppstått sykdom var årsak til at de oppsøkte legevakten fremfor fastlegen på dagtid (12).

De aller sykeste (rød respons og omtrent halvparten av gul respons, n=120) var dessu ike inkluderti kye in synes denfor det er tankevekkende at over halvparten av pasientene oppfatter seg selv som alvorlig syke. Det kan tenkes at noen pasienter oppgav en høyere alvorlighetsgrad for å rettferdiggjøre at de valgte legevakten fremfor fastlegen. Vi synes det er påfallende at så mange pasienter mente de trengte legehjelp innen svært de trengte legehelp inen svært korte ogsa ble horte gronn responstuppe. V mener mange pasienter burde ventet med å oppsøke legevakten og heller kontaktet fastlegen, men det er kanskje mange som ikke vet at legevakten bare skal brukes ved øyeblikkelig hjelp. Her kan det være stor forskjell på hvordan pasienter og helsepersonell definerer begrepet «øyeblikkelig hjelp». Pasienter vil kanskje mene at reverk med smerter hos barn rer soll vil katerise er panle gronn respons). Vi mener funnene fra denne undersøkelsen avdekker at det er viktig med informasjon til befolkningen om hvilket tilbud fastlegekontorene og legevaktene gir. En bør derfor i større grad informere om hvilke medisinske problemstillinger som horer hjemme på legevakten, og hvilke som kan vente til fastlegekontoret åpner. Seks prosent av pasientene i vår undersøkelse svarte at de kke trodde fastlegen kunne gi den hjelpen de trengte. Det kan tyde på at flere pasienter ikke vet t fastlegen også yter hjelp ved for ksempel skader/kutt, og at det t behov for bedre informasjo om hvilket helsetilbud fastlege kan gi.

En undersøkelse fra NordNorge i 1987 viste at flertallet av pasientene ønsket å oppsøke sin faste primærlege, selv om dette medførte venting (13). I undersø kelsen til Steen og Hunskår fr Bergen i 2003 var omlag halvparten av pasientene villige til vente dersom de var sikret time hos fastlegen neste dag (14). I vår undersøkelse ville kun en femde av pasientene ha utsatt legevaktbesøket til neste dag selv om de var sikret time hos fastlegen da. Selv blant dem som oppgav ære mindre alvorlig syke, var det over 40 prosent som ikke syntes time hos fastlegen neste dag var noe godt alternativ. Muligens er befolkningens krav og forventinger til å få legehjelp akkura når det måtte passe dem større n enn tidligere. Førtifire personer prosent i var undersokelse svarte at det var praktisk vanskelig gå til fastlege på dagtid. Mulige rsaker kan være at arbeidsgivere arbeidstiden og at svort mange mennesker i dag er i arbeid. tillegg kan det hende at noen yrkesaktive foreldre synes det e enklere å ta barn med til lege pa ttermiddag, kveld og helg enn måtte ta fri fra jobb. Det kan ogs hende at mennesker i dag er mer engstelige for egen helse enn de kke spiller noen rolle om det legevaktlegen eller fastlegen som gir den hielpen som trengs. Kanje skyldes det at svert mange problemstillinger på legevakt

relativt ukompliserte og at det dermed ikke er så viktig hvem som undersøker pasienten. Trettiåtte prosent svarte at fastlegen vanligvis er den som gir best hielp. Det kan ter med kroniske og at pasiensykdommer foretrekker å gå til fastlegen hvor de kjenner både legen og medhjelperne, også når de har akutt sykdom.

Fra enkelte legekontor var den relative pasientsøkningen til legevakt spesielt høy. Undersøkelsen til Nyen og Lindbrk Skien i 2002 (15) vis Lindbæk spredning i legevaktsøkningen mellom de ulike legekontor pasientpopulasjoner. Ett legekontor i vår undersøkelse skilte seg ut med svært mange kontakter, sannsynligvis fordi kontoret var uten lege i deler av perioden studien pågikk. Kontoret hadde dessuten svært få listepasienter, sã det var et begrenset antall pasienter som giorde det store utslaget i undersøkelsen. Pasienter fra små legekontor med mindre en 2000 listepasienter, beliggende

Det er kanskje $\checkmark$ mange som ikke vet at legevakten bare 
ler å gå til fastlegen dagen etter. Pasienter tilhørende legekontor med omtrent lik avstand til legevakten, lik listelengde og samme antall leger i praksis kunne ha svært forskjellig legevaktsøkning. Dette gjaldt praksiser både i og utenfor Arendal kommune. Ut fra denne undersøkelsen er det ikke mulig å si noe om årsakene til dette, men det kan være ulike rutiner ved legekontorene for hvor syke pasientene må være for å tilby dem time samme eller neste dag.

Sykepleierne er i praksis de som vurderer om pasienten skal vurderes ved legevakten. Det tilstrebes en enhetlig praksis ved at medisinske prosedyrer etableres og gjennomgås i fellesskap i intern undervisning.

I vår undersøkelse fikk 43 prosent av pasientene som kom til konsultasjon ved legevakten utdelt spørreskjemaet. Sannsynligvis er hovedforklaringen til den lave utdelingsprosenten at noen sykepleiere glemte å dele ut skjemaet, uavhengig av sykdommens alvorlighet. Pasienter som trengte hjelp umiddelbart var ekskludert fra undersøkelsen. Sykepleierne fortalte at de som trengte hjelp umiddelbart var både rød respons og anslagsvis opp mot halvparten av gul respons (selv om en tilstand ikke er livstruende, kan pasienten likevel trenge hjelp umiddelbart). I Vakttårnundersøkelsen for mars 2007 ( $\mathrm{n}=1425$ ) (egne data) er det registrert 1 prosent rød respons og 16 prosent gul respons (rundt 8 prosent som trengte hjelp umiddelbart). Dette betyr at en svært stor andel av pasientene som ikke fikk utdelt skjema hadde en sykdom med liten hastegrad. I tillegg var det en del henvendelser innen grønn respons-gruppen som ikke fikk skjema utdelt de gangene det var så kort ventetid at pasienten gikk direkte inn til legen.
Det styrker vår antakelse om studiepopulasjonens representativitet at fordelingen av alder, kjønn og ukedag er sammenfallende med resultatene fra Vakttårnundersøkelsen, hvor det ble registrert data fra nesten dobbelt så mange konsultasjoner. Ifølge denne undersøkelsen var antall konsultasjoner ved Legevakten i Arendal lavest på onsdager (8 prosent) og mandager ( 9 prosent) og høyest på lørdager (25 prosent) og søndager (22 prosent). Dette tilsvarer funnene fra undersøkelsen vår hvor det også var færrest pasienter onsdager (6 prosent) og mandager (9 prosent) og flest lørdager (27 prosent) og søndager (20 prosent).

Nesten hver tredje konsultasjon ved legevakten gjaldt barn under 15 år. Dette er i tråd med tallene fra NAV 2006 (11). Totalt sett var det noe flere kvinner enn menn som oppsøkte Legevakten i Arendal.

Det relativt høye antallet pasienter som deltok i studien, og den høye svarprosenten (92 prosent) blant dem som fikk utdelt spørreskjemaet, er en styrke ved studien. Vi mener derfor at undersøkelsen peker på en del viktige faktorer som påvirker pasienters valg mellom fastlege og legevakt.

\section{KONKLUSJON}

Stengt fastlegekontor og akutt sykdom utenom vanlig kontortid var de to vanligste årsakene til at pasientene oppsøkte legevakten fremfor fastlegen. Legevaktsøkningen varierte mye etter hvilket fastlegekontor og hvilken kommune pasienten tilhørte. Over halvparten av pasientene vurderte sin medisinske tilstand som alvorlig eller meget alvorlig. Kun 20 prosent av pasientene mente de kunne vente til neste dag.

En stor takk til sykepleierne ved Legevakten i Arendal som delte ut og tok $i$ mot alle spørreskjemaene.

\section{LITTERATUR}

1. Helse-og omsorgsdepartementet. Legevakt og akuttmedisin. http://www. regjeringen.no/nb/dep/hod/tema/ Helse-og_omsorgstjenester_i_kommunene/Legevakt-og-akuttmedisin. html? id=441858 (1.9.2008).

2. Den norske lægeforening. Interkommunal legevakt (7/2005). Gode legevaktsordninger gir trygghet for befolkningen. http://www.legeforeningen.no/index. gan?id=90578\&subid=0 (1.9.2008).

3. Helse- og sosialdirektoratet. Veileder for etablering og drift av interkommunale legevaktordninger. Sosial- og helsedirektoratet, 9/2003.

4. Norsk index for medisinsk nødhjelp. Utgave 2.1 2005. Stavanger: Åsmund S. Lærdal A/S

5. Høie I. Fornøyd med fastlegen men oppsøker legevakten. Tidsskr Nor Lægeforen 2006; 126: 3348.

6. Hasvold T. Fastlegeordningen - bare en strukturreform? Tidsskr Nor Lægeforen 2004; 124: 475.

7. Tollefsen LH, Amundsen A, Kolstrup N. Fastlegeordningens betydning for legevakts $\varnothing$ kningen. Tidsskr Nor Lægeforen 2003; 123: 1327-9.

8. Jøsendal 0, Aase S. Legevaktaktivitet før og etter innføring av interkommunal legevakt og fastlegeordning. Tidsskr Nor Lægeforen 2004; 124: 506-7.

9. Vakttårnprosjektet. Nasjonalt kompetansesenter for legevaktmedisin, 2007. http://www.unifobhelse.uib.no/index.php? Gruppe $=15 \&$ Lang $=$ nor $\& I D=$ Prosjekter \&co unter=123 (1.9.2008).

10.NAV Min Fastlege. https://tjenester. nav.no/minfastlege/innbygger/fastlegesok.do (1.6.2007).

11.NAV rapport nr. 4/2007. Hva foregår på legekontorene? Arbeids-og velferdsdirektoratet. Statistikk og utredning. Oktober 2007. http://www.nav.no/ binary/805363647/file (1.9.2008).

12. Werner EL. Legevakten i Arendal - en ny modell for interkommunal legevakt. Tidsskr Nor Lægeforen 2001; 121: 1704-6.

13. Straume B, Forsdahl A. Tilgjengelighet og ventetid hos primærlegen. Pasientunders $\emptyset$ kelsen i Nord-Norge 1987. Tidsskr Nor Lægeforen 1990; 110 : $3484-8$.

14. Steen K, Hunskaar S. Fastlegeordningen og legevakt i Bergen. Tidsskr Nor Lægeforen 2004; 124: 365-6.

15. Nyen B, Lindbæk M. Legevaktsøkning og fastlegeordning. Tidsskr Nor Lægeforen 2004 ; 124 : 508-9. 